\title{
POSSIBILITY FOR IMPROVING OVARIAN ACTIVITY, CYTOPLASMIC MATURATION, FERTILIZATION AND DEVELOPMENTAL COMPETENCE IN VITRO OF OOCYTES BY ADMINISTRATION OF DOE RABBITS WITH GREEN TEA EXTRACT
}

\author{
A.E. Abdel-Khalek ${ }^{1}$; M.A. El-Harairy ${ }^{1}$; Sara F. Fouda ${ }^{2}$; Lamiaa Y. El-Bnawy ${ }^{1}$ and \\ I.T.El-Ratel. ${ }^{3}$ \\ ${ }^{I}$ Department of Animal Production, Faculty of Agriculture, Mansoura University, Egypt. \\ ${ }^{2}$ Department of Poultry Productions, Faculty of Agriculture, Mansoura University, Egypt. \\ ${ }^{3}$ Department of Poultry Production, Faculty of Agriculture, Damietta University, Egypt.
}

Corresponding Author: ibrahim.talat81@yahoo.com

SUMMARY

$\mathrm{T}$ he aim of this study was to evaluate the effect of oral administration of doe rabbits with green tea extract polyphenols (GTPs) at different levels on ovarian activity, oocyte quality, in vitro maturation, fertilization and development of oocytes. Total of 12 mature NZW doe rabbits (5-6 months of age, 2.5-3.20 kg LBW) were used in this study. Does were divided into 3 similar groups, (n=4). The $1^{\text {st }}$ group $(\mathrm{G} 1)$ was control, while does in the $2^{\text {nd }}(\mathrm{G} 2)$ and $3^{\text {th }}(\mathrm{G} 3)$ groups were given daily for one month oral $1 \mathrm{ml}$ distilled water containing 200 and $400 \mathrm{mg} / \mathrm{kg} \mathrm{LBW}$ of GTPs, respectively. At the end of treatment period, does in each group were slaughtered and immediately ovaries were removed and oocytes were collected by slicing technique for evaluation. Only compact-cumulus oocytes (COCs) were in vitro matured and fertilized. Results showed that ovarian weight relative to LBW, oocyte number/doe and recovery rate of oocyte were higher $(\mathrm{P}<0.05)$ in $\mathrm{G} 2$ and $\mathrm{G} 3$ than in $\mathrm{G} 1$. Number of visible follicles/doe was not affected by treatment. Frequency distribution was higher $(\mathrm{P}<0.05)$ for COCs and lower $(\mathrm{P}<0.05)$ for denuded oocytes in G2 and G3 as compared to G1. Frequency distribution of both expanded and partial denuded oocytes were not affected by treatment. Percentage of full expanded oocytes was the highest $(\mathrm{P}<0.05)$ in $\mathrm{G} 2$, followed by G3, while G1 showed the lowest $(\mathrm{P}<0.05)$ values. Percentage of partial expansion oocytes was higher $(\mathrm{P}<0.05)$ in $\mathrm{G} 3$ than in $\mathrm{G} 1$ and $\mathrm{G} 2$. Fertilization rate was higher $(\mathrm{P}<0.05)$ in G2, followed by G3, while G1 showed the lowest $(\mathrm{P}<0.05)$ values. Percentage of blastocysts was higher $(\mathrm{P}<0.05)$ in G2 and G1 than in G3. Percentage of morulae, and degenerated and un-cleaved embryos were not affected by GTPs treatment. In conclusion, treatment of doe rabbits with green tea extract at a level of $200 \mathrm{mg} / \mathrm{kg} \mathrm{LBW}$ as daily oral dose for one month is recommended to enhance ovarian activity, oocyte quality, cytoplasmic maturation and in vitro embryo production.

Keywords: Doe rabbits, green tea, oocyte categories, maturation, fertilization in vitro.

\section{INTRODUCTION}

Ovarian cyclic activity induces some of follicles to initiate growth towards ovulation, but subsets of oocytes are capable to support maturation, fertilization and early embryo development only in growing follicles (Mermillod et al., 2008). In vitro embryo production (IVEP) system includes three major steps, in vitro maturation (IVM) of immature oocytes, in vitro fertilization (IVF) of matured oocytes and in vitro culture (IVC) of presumptive embryos, until transferred or cryopreserved for future use (Gandolfi et al., 2005; Zhu et al., 2007). The IVM is one of the essential steps in the IVF process for the success of IVEP (Barakat et al., 2014). Oocyte maturation includes cytoplasmic maturation in term of some changes for oocyte development to be fertilized and pre implant; and nuclear maturation to the resumption of meiosis and development to metaphase-II stage (Merlo et al., 2005). Mammalian oocyte developmental competence was reported to be negatively affected by increasing oxidative stress in in vitro than in vivo derived oocytes (Moor et al., 2001; Rangasamy et al., 2009). It was demonstrated in previous studies that higher levels of reactive oxygen species (ROS) produced through IVC can adversely affect many aspects of culture condition, which had higher $\mathrm{O}_{2}$ concentration, and subsequently reduces fertilization and embryo development in vitro (Tatemoto et al., 2004; Bedaiwy et al., 2004). Various antioxidant agents exist in cells and their functions are complementary in the 
cellular defense system, which are necessary for improvement of oocytes IVM (Maleki et al., 2014). In the animal body, oocytes can be protected from oxidative stress by free radical and enzymatic scavenging antioxidant that exist within the follicular and oviductal fluid (Gupta et al., 2010). Therefore, treatment with antioxidants such as Coenzyme Q10 or L-carnitine can improve oocyte quality, which is important for IVM, IVF and IVC into viable offspring (Younan et al., 2015).

Green tea (GT) has been used as a medicinal plant, which obtained from the leaves and the leaf buds of the plant Camellia sinensis (Kádasi et al., 2014). It has been used as an antioxidant, antiviral and antibacterial agents, as well as it had enzyme-inhibitory, anti-radiation and anti-cancerous effects (Reto et al., 2014). The main components of GT are polyphenols (GTPs); 50-80\% of polyphenols are represented by special flavonoids - catechins, especially epigallocatechin-3-gallate (EGCG) (Khan et al., 2006). The EGCG is one of the most active and bioavailable components of GT catechins acting as a strong antioxidant and potent scavenger of free radicals and ROS in biological system (Schroeder et $a l .$, 2003). Treatment with GT during IVM improved fertilization and developmental competence of bovine (Wang et al., 2007) and sheep (Barakat et al., 2014) oocytes and this improvement was correlated with the increase of intracellular glutathione concentration after IVM of oocytes (Wang et al., 2007). According to our knowledge, no studies have been done concerning the effects of oral GT extract administration on ovarian activity and in vitro production of rabbit embryos.

Thus, the aim of the current study was to evaluate ovarian activity, recovery, quality, and in vitro cytoplasmic maturation, fertilization and development of oocytes recovered from doe rabbits treated with GT extract.

\section{MATERIALS AND METHODS}

This study was carried out at the Laboratory of Physiology and Biotechnology, belonging to Animal Production Department, Faculty of Agriculture, Mansoura University. All types of chemicals and media were purchased from Sigma-Aldrich Company (St. Louis, MO).

A total of 12 mature New Zealand white (NZW) doe rabbits (5-6 months of age and 2.5-3.20 kg LBW) were used in this study as oocyte donors. Does $(n=12)$ were divided randomly into three groups (4 does each). The $1^{\text {st }}$ group (G1) was control, while does in the $2^{\text {nd }}(\mathrm{G} 2)$ and $3^{\text {rd }}(\mathrm{G} 3)$ groups were given daily an oral dose of $1 \mathrm{ml}$ distilled water containing 200 and $400 \mathrm{mg} / \mathrm{kg} \mathrm{LBW}$ of GT extract for one month as treatment period, respectively. At the end of treatment period, does in each group were slaughtered and ovaries were immediately removed, washed by $\mathrm{NaCl}$ solution $(0.9 \%)$ and dried by cleaning paper. Follicular oocytes were collected by slicing technique in $5 \mathrm{ml}$ of harvesting medium (Dulbecco's Phosphate buffer saline, DPBS) supplemented with $10 \%$ fetal calve serum (FCS, v:v) and $50 \mu \mathrm{g} / \mathrm{ml}$ gentamycin in Petri dishes. Oocytes were examined under stereomicroscopy and classified according to the cumulus layers and homogeneity of ooplasm as described by Ravindranatha et al. (2003) into compact (COCs), expanded, partial denuded and denuded cumulus oocytes.

Only COCs in each group were rapidly washed three times of tissue culture media (TCM-199 as a maturation medium) containing $10 \%$ FCS $(v: v), 10 \mathrm{IU} / \mathrm{ml}$ hCG, $10 \mathrm{IU} / \mathrm{ml}$ PMSG, $1 \mu \mathrm{g} / \mathrm{ml}$ estradiol$17 \alpha$ and $50 \mu \mathrm{g} / \mathrm{ml}$ gentamycin. The maturation medium had $\mathrm{pH}$ value of 7.2-7.4, osmolality of 280-300 mOsmol/kg and filtered by $0.22-\mu \mathrm{m}$ millipore filter (Milieux GV, milpore, Cooperation Bedford MOA). Each $500 \mu \mathrm{l}$ from prepared maturation medium was placed into four well dishes and covered by sterile mineral oil. Before placing the COCs in culture dishes, the medium was incubated in $\mathrm{CO}_{2}$ incubator $\left(5 \% \mathrm{CO}_{2}\right.$, at $38^{\circ} \mathrm{C}$ with saturated humidity) for at least 60 minutes. The COCs were cultured in the maturation medium and incubated under the same conditions for $20 \mathrm{~h}$.

The morphology of in vitro matured oocytes was evaluated for full-, partial- and non-expanded cumulus layer according to Sreenivas et al. (2013). The maturation rate (cytoplasmic maturation) was expressed only in term of percentage full-expanded oocytes.

For IVF, semen was collected from fertile rabbit bucks and the jelly mass of each ejaculate was discarded and net volume of 20 ejaculates was pooled for sperm capacitation. The DPBS supplemented with $3 \mathrm{mg} / \mathrm{ml}$ bovine serum albumin, $35 \mu \mathrm{g} / \mathrm{ml}$ heparin and $50 \mu \mathrm{g} / \mathrm{ml}$ gentamycin was used. Fertilization droplets were prepared by pipetting $50 \mu \mathrm{l}$ of fertilization medium under sterile liquid paraffin oil and incubated at $38^{\circ} \mathrm{C}$ for $2 \mathrm{~h}$ in $5 \% \mathrm{CO}_{2}$ in air and high humidity. About $50 \mu \mathrm{l}$ of washing media was added to each droplet with 8-12 oocytes followed by adding $2 \mu \mathrm{l}$ of prepared semen and 
then incubated together at $38^{\circ} \mathrm{C}$ for $24 \mathrm{~h}$ in $5 \% \mathrm{CO}_{2}$ in air. Fertilization rate after $24 \mathrm{~h}$ and developmental competence of embryos at different embryonic stages after 5 days were investigated.

Data were analyzed by one-way ANOVA using GLM procedures of SAS (2001). Duncan's Multiple Range Test was set at $\mathrm{P}<0.05$ to determine the significant differences among means according to Duncan (1955).

\section{RESULTS AND DISCUSSION}

\section{Ovarian activity:}

Relative ovarian weight, and number of oocytes per doe and recovery rate of oocytes significantly $(\mathrm{P}<0.05)$ improved by both GT extract treatments in G2 and G3 as compared to G1. However, number of visible follicles was not affected by treatment (Table 1).

It is of interest to note that increasing relative ovarian weight of does in both treatment groups was associated with insignificant increase in number of visible follicles. Also, increasing number of oocytes and their recovery was attributed to presence of numerous follicles on the ovaries of treatment groups. In accordance with the present results, GT consumption was reported to cause modulation gonadotropin levels, reducing insulin resistance and improving the ovarian morphology in rat (Ghafurniyan et al., 2015) and GT extract administration for 42 days significantly increased the number of primary, growing, and antral follicles in mice (Sanaei et al., 2014).

In addition, Zhong and Zhou (2013) found that natural plant derived antioxidants may exhibit beneficial or detrimental effects in animal ovary functions, in terms of increased ovarian weight, number of large follicles and recovered oocytes of doe rabbits treated with coenzyme Q10 or Lcarnitine as daily oral for 21 days (Younan et al., 2015).

\section{Oocyte quality:}

Frequency distribution of compact oocytes was significantly $(\mathrm{P}<0.05)$ higher, while that of denuded oocytes was significantly $(\mathrm{P}<0.05)$ lower in G2 and G3 as compared to G1. However, effect of treatment on frequency distribution of both expanded and partial denuded oocytes was not significant (Table 2).

This means that GT extract treatments had an impact on quality of recovered oocytes, in terms of increasing yield of compact oocytes as compared to control, being insignificantly better for treatment of doe rabbits with GT extract at a level of $200 \mathrm{mg} / \mathrm{kg} \mathrm{LBW}$.

Improving oocyte quality of doe rabbits in G2 may be related to follicular size. In this respect, Wani et al. (2000) found a higher correlation between follicle quality and the distribution of different oocyte categories. Similarly, Younan et al. (2015) reported that treatment with L-carnitine as antioxidant significantly $(\mathrm{P}<0.05)$ increased frequency distribution of compact cumulus oocytes in rabbits.

\section{Cytoplasmic maturation:}

According to degree of cumulus expansion, maturation rate in term of the percentage of full expanded oocytes was significantly $(\mathrm{P}<0.05)$ the highest in $\mathrm{G} 2$, followed by G3, while G1 showed the lowest values. (Table 3). This means that GT extract treatment at a level of $200 \mathrm{mg} / \mathrm{kg} \mathrm{LBW}$ (G2) had impact on maturation rate of oocytes.

Some previous studies confirmed that maturation rate of oocytes significantly increased when oocytes were matured in the presence of GT extracts as a source of antioxidant compared with the control. In this respect, Barakat et al. (2014) reported that adding GT extract $(0.3 \mathrm{mg} / \mathrm{ml})$ to maturation medium improved the maturation rate in sheep. Also, Spinaci et al. (2008) showed that high EGCG concentrations $(25 \mu \mathrm{g} / \mathrm{ml})$ in maturation medium could improve IVM of pig oocytes. Using other agents as antioxidants, coenzyme Q10 treatment increased percentage of full cumulus expansion oocytes as compared to control in rabbits (Younan et al., 2015) and addition of saffron aqueous extract as antioxidants to maturation medium increased the maturation rate of mouse oocytes (Maleki et al., 2014).

Generally, antioxidants addition to maturation medium improved the meiotic competence of mammalian oocytes by holding back the apoptosis of granulosa cells and enhancing its mitochondrial activity (Somfai et al., 2011). In our study, phenol and flavonoid compounds, which are widely found 
as secondary metabolites in plants, are important due to their ability to serve as antioxidants (Wang et al., 2008). The GT components such polyphenols are free radicals scavengers (Lau et al., 2016) and flavonoids have been shown to be effective scavengers of most types of oxidizing molecules, including singlet oxygen and various free radicals (Maleki et al., 2014). The recorded improvement in oocyte maturation in our study might be due to antioxidant effect of GT extract, which could be attributed to the protection of oocytes against oxidative stress and increased glutathione synthesis level during maturation, indicating that its influence is more prominent on the cytoplasmic maturation rather than nuclear maturation (Wang et al., 2007).

\section{Fertilization rate and developmental competence in vitro:}

Treatment of doe rabbits with both levels of GT extract (G2 and G3) showed significantly $(\mathrm{P}<0.05)$ marked improvement in fertilization rate of in vitro matured oocytes as compared to control (G1). Meanwhile, only G2 yielded significantly $(\mathrm{P}<0.05)$ the highest percentage of embryos at morula and blastocyst stages and the lowest percentage of degenerated embryos, but the differences were significant $(\mathrm{P}<0.05)$ only for embryos at blastocyst stage (Table 4$)$.

Such findings indicated positive effect of GT extract treatment of doe rabbits on embryo production rate. In accordance with the present results, addition of GT extract during IVM improved the morula and blastocyst formulation rate in sheep (Barakat et al., 2014), mouse (Roth et al., 2008) and bovine (Wang et al., 2007). Also, the addition of natural antioxidants such as saffron aqueous extract (Maleki et al., 2014), cysteine and cystine (Ali et al., 2003), during IVM increased IVF and development to the blastocyst stage.

Oxidative stress has a negative effect on IVM and embryonic development of oocytes (Matos et al., 2002). Oocytes and embryos produce endogenous ROS by various enzymatic actions during the metabolic process (Harvey et al., 2002; Gordon, 2003). There is evidence that ROS in in vitro oocytes maturation affect IVEP in bovine (Geshi et al., 2000). These are formed when molecular $\mathrm{O}_{2}$ is utilized as an electron acceptor during redox reaction in cells. They damage cell membranes, protein and DNA (Yuh et al., 2010; Sudano et al., 2010). Therefore, ROS must be inactivated continuously in order to maintain only the small amount necessary to maintain normal cell functions (Sudano et al., 2010). Addition of antioxidant alone is not enough to protect ROS, so selection of antioxidant and its concentrations are very critical. Hence improving and increasing knowledge concerned with antioxidant and their mechanisms may contribute the development of embryos and evaluation methods of embryo/oocytes quality in in vitro culture system (Öztürkler et al., 2010). In general, the GT extract have been shown to be useful as antidiabetic, antitumor, antiarthritic, and antioxidant agents (Raza and John, 2005). The antioxidant properties of GT or its extract are thought to be associated with their ability to stimulate the antioxidant defense metabolism through redox regulated transcription factors and mitogen activated protein kinase-dependent cell cycle regulation (Williams et al., 2004).

\section{CONCLUSION}

The current study may suggest that treatment of doe rabbits with green tea extract, as polyphenolic compounds, at a level of $200 \mathrm{mg} / \mathrm{kg} \mathrm{LBW}$ as daily oral dose for one month is recommended to enhance ovarian activity, oocyte quality, cytoplasmic maturation and in vitro embryo production in rabbits.

\section{REFERENCES}

Ali, A.A., J.F. Bilodeau and M.A Sirard (2003). Antioxidant requirements for bovine oocytes varies during in vitro maturation, fertilization and development. Theriogenology, 59: 939-949.

Barakat, I. A. H., R. A. Ahmad and M. R. Ahmed (2014). Antioxidant effect of green tea leaves extract on in vitro production of sheep embryos. Pakistan J. Zool., 1: 167-175.

Bedaiwy, M.A., T. Falcone, M.S. Mohamed, A.A.N. Aleem, R.K. Sharma and S.E. Worley (2004). Differential growth of human embryos in vitro: role of reactive oxygen species. Fertil Steril, 82:593-600.

Duncan, D.B., 1955. Multiple Range and Multiple F-Test. Biometrics, 11: 1-42. 
Gandolfi, F., T.A.L., Brevini, F. Cillo, and S. Antonini (2005). Cellular and molecular mechanisms regulating oocyte quality and the relevance for farm animal reproductive efficiency. Rev. Sci. Tech. off. Int. Epiz., 24: 413-423.

Geshi, M., N, Takenouchi, N. Yamauchi and T. Nagai (2000). Effects of sodium pyruvate in non-serum maturation medium on maturation, fertilization, and subsequent development of bovine oocytes with or without cumulus cells. Biol. Reprod., 63: 1730-1734.

Ghafurniyan, H.,A. Mahnaz, N. Mohammad and K. Latifeh (2015). The Effect of Green Tea Extract on Reproductive Improvement in Estradiol Valerate-Induced Polycystic Ovary Polycystic Ovarian Syndrome in Rat. Iranian Journal of Pharmaceutical Research,14: 1215-1233.

Gordon, I. (2003). Laboratory production of cattle embryos: Maturing the oocyte, 2th edition, CABI publishing, Cambridge, MA 02138.

Gupta, S., L. Sekhon, Y. Kim and A. Agarwal (2010). The role of oxidative stress and antioxidants in assisted reproduction. Curr. Women's Hlth. Rev., 6: 227-238.

Harvey, A.J., K.L. Kind and J.G. Thompson (2002). REDOX regulation of early embryo development. Reproduction, 123: 479-486.

Kádasi, A., A. Kolesárová, N. Maruniaková1, R. Grossmann, A. Štochmal'ová, R. Alexa, A. V. Sirotkin (2014). The effect of green tea extract-epigallocatechin gallate (EGCG) on porcine ovarian granulosa cell. J Microbiol Biotech Food Sci, 3:107-109.

Khan, N., F. Afaq, M. Saleem, N. Ahmad and H. Mukhtar (2006). Targeting multiple signaling pathways by green tea polyphenol (-) - epigallocatechin-3-gallate. Canser Research, 66, 2500-2505.

Lau, S.O., E.N. Georgousopoulou, J. Kellett, J. Thomas and A. McKune (2016). The effect of dietary supplementation of green tea catechins on cardiovascular disease risk markers in humans: A systematic review of clinical trials. Beverages, Vol. 2. 10.3390/beverages2020016.

Maleki, E. M., E. Hussein, B. R. Mohammad, E. Bita, Sh. A. Hossein, A. G. Narenji and A. Reyhane (2014). A comparative study of saffron aqueous extract and its active ingredient, crocin on the in vitro maturation, in vitro fertilization, and in vitro culture of mouse oocytes. Taiwanese Journal of Obstetrics \& Gynecology, 53:21-25.

Matos, D.D., B, Gasparrini, S.R, Pasqualini and J.G. Thompson. (2002). Effect of glutathione synthesis stimulation during in vitro maturation of ovine oocytes on embryo development and intracellular peroxide content. Theriogenology, 57: 1443-1451.

Merlo, B., I. Eleonora, Z. Daniele, P. Francesca and B. Stefano (2005). Effect of EGF on in vitro maturation of domestic cat oocytes. Theriogenology, 63: 2032-2039.

Mermillod, P., R. Dalbiès-Tran, S. Uzbekova, A.Thélie, J.M. Traverso, C. Perreau, P. Papillier and P. Monget (2008). Factors affecting oocyte quality: who is driving the follicle?. Reprod. Domest. Anim., 2:393-400.

Moor, R., Y. Dai, R. Geisert, H. Niemann and C. Doberska (2001). Maturation of pig oocytes in vivo and in vitro. Reprod Suppl, 58:91-104.

Öztürkler, Y., S. Yildiz, Ö. Güngör, Ş.M. Pancarci, C. Kaçar and U.Ç Ari (2010). The effects of Lergothioneine and L-ascorbic acid on the in vitro maturation (IVM) and embryonic development (IVC) of sheep oocytes. Kafkas Univ. Vet. Fak. Derg., 16: 757-763.

Rangasamy, S., K. Kulasekar, S. Balasubramanian, G.D. Raj and C. Verrapandian (2009). Influence of antioxidant supplementation on in vitro production of bovine embryos. Ind. Vet. J., 86: 148-150.

Ravindranatha, B.M. S. Nandi, P.S.P. Gupta and P.V. Sarma (2003). In vitro effects of different levels of commercially available PMSG on oocyte maturation. Buffalo J., 1:101-107.

Raza, H. and A. John (2005). Green tea polyphenol epigallocatechin-3-gallate differentially modulates oxidative stress in PC12 cell compartments. Toxicol Appl Pharmacol, 207: 212-220.

Reto, M., C. Almeida, J. Rocha, B. Sepodes and M.E. Figueira (2014). Green tea (Camellia sinensis): Hypocholesterolemic effects in humans and anti-inflammatory effects in animals. Food Nutr. Sci., 5: 2185-2194.

Roth, Z., A. Aroyo, S. Yavin and A. Arav, 2008. The antioxidant epigallocatechin gallate (EGCG) moderates the deleterious effects of maternal hyperthermia on follicle-enclosed oocytes in mice. Theriogenology, 70: 887-889.

Sanaei, N., J, Abeshnas and R. Kheirandish (2014). The effect of green tea extract on mice model of follicles in the ovaries. The second national conference on medicinal plants and sustainable agriculture; (Persian). 
SAS, 2001. SAS/Stat. User's Guide Static's, Ver., 6.06 4th Ed. SAS Institute Inc. Cary, NC.

Schroeder, P., L.O. Klotz and H. Sies (2003). Amphiphilic properties of (-)-epicatechin and their significance for protection of cells against peroxynitrite. Biochem. Biophys. Res. Commun, 307: 69-73.

Somfai, T., M. Kaneda, S. Akagi, S. Watanabe and S. Haraguchi (2011). Enhancement of lipid metabolism with L-carnitine during in vitro maturation improves nuclear maturation and cleavage ability of follicular porcine oocytes. Reprod Fertil Dev., 23:912-920.

Spinaci, M., Volpe, S., De Ambrogi, M., Tamanini, C. and Galeati, G. (2008). Effects of epigallocatechin- 3-gallate (EGCG) on in vitro maturation and fertilization of porcine oocytes. Theriogenology 69:877-885.

Sudano, M.J., M.C.C. Mattos, C.B. Fernandes, R.R, Mazieiro and F.C Landim-Alvarenga (2010). In vitro production of bovine embryos using Sigma antioxidant supplement ${ }^{\circledR}$, $\alpha$-tocopherol and Lascorbic acid. Anim. Reprod., 7: 42-48.

Sreenivas, D., Kaladhar, D.S.V.G.K., Yarla, N.S., Thomas, V.M. and PalniSamy, A. (2013). Effect of protein supplementation on in vitro maturation of sheep oocytes and in vitro culture of preimplantation with -tocopherol supplementation in crlaa medium on sheep embryos to the blastocyst stage. J Aller Ther, 4: 133-140.

Tatemoto, H., N. Muto, I. Sunagawa, A. Shinjo and T. Nakada. (2004). Protection of porcine oocytes against cell damage caused by oxidative stress during in vitro maturation: role of superoxide dismutase activity in porcine follicular fluid. Biol Reprod, 71:1150-1157.

Wang, Y.C., Y.C. Chuang and H.W. Hsu (2008). The flavonoid, carotenoid and pectin content in peels of citrus cultivated in Taiwan. Food Chem, 106:277-284.

Wang, Z.G., S.D. Yu and Z.R. Xu (2007). Improvement in bovine embryo production in vitro by treatment with green tea polyphenols during in vitro maturation of oocytes. Anim Reprod Sci, 100:22-31.

Wani, N.A., Wani, G.M., Khan, M.Z. and Salahudin, S. (2000). Effect of oocyte harvesting techniques on in vitro maturation and in vitro fertilization in sheep. Small Rumin Res, 36:63-67.

Williams, R.J., J.P. Spencer and C. Rice-Evans. (2004). Flavonoids: antioxidants or signalling molecules? Free Radic Biol Med, 36: 838-849.

Younan, G.E., El-Nagar, H.A., Wafa, W.M., El-Ratel, I.T. and Abdel-Khalek, A.E. (2015). Litter size, ovarian characteristics and oocyte in vitro maturation and fertilization of rabbits administrated with coenzyme Q10 and L-carnitine. Egypt. J. Nutr. Feeds, 18: 227-236.

Yuh, H.S., D.H. Yu, M.J. Shin, H.J. Kim, K.B. Bae, D.S. Lee, H.C. Lee, W.K. Chang, S.B, Park, S.G. Lee, H.D. Park, J.H. Ha, B.H. Hyun and Z.Y. Ryoo (2010). The effects of various antioxidants on the development of parthenogenetic porcine embryos. In vitro Cell. Dev. Biol. Anim., 46: 148-154.

Zhong, R. and Zhou, D. (2013). Oxidative Stress and Role of Natural Plant Derived Antioxidants in Animal Reproduction. Journal of Integrative Agriculture, 12: 1826-1838.

Zhu, S.X., Z. Sun and J.P. Zhang (2007). Ovine (Ovis aries) blastula from an in vitro production system and isolation of primary embryonic stem cells. Zygote, 15:35-41. 
إمكانية تحسين النشاط المبيضى، النضج السيتوبلازمى،الإخصاب والتطور المعلى للبويضات بمعاملة أمهات

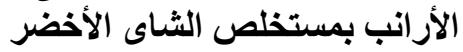

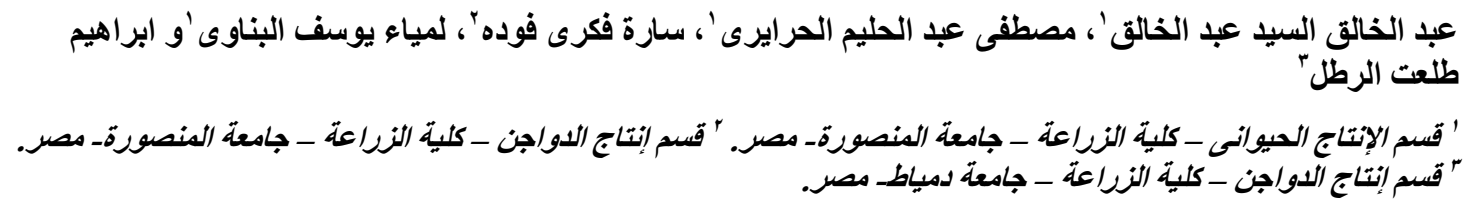

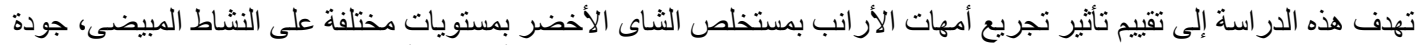

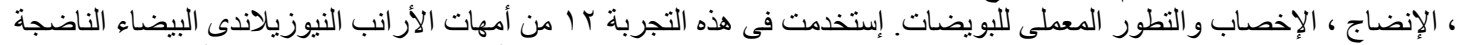

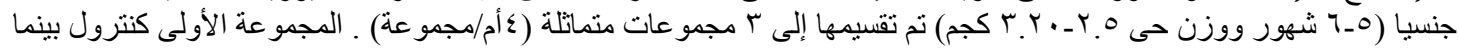

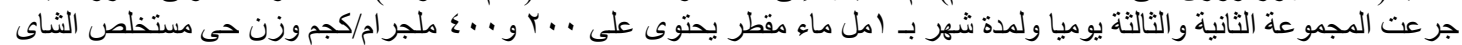

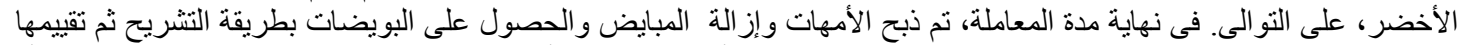

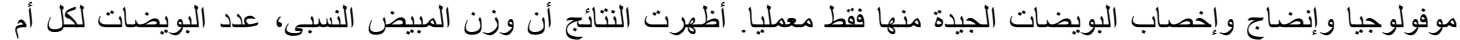

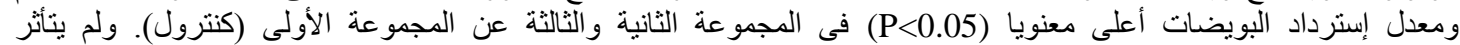

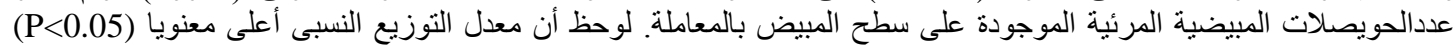

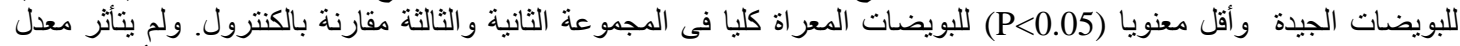

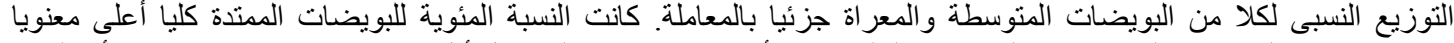
(P<0.05)

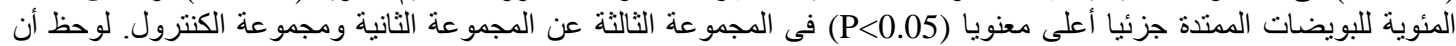

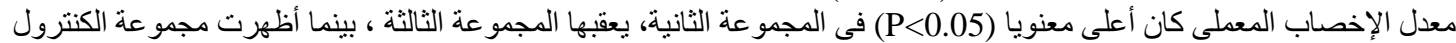

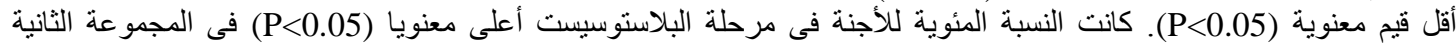

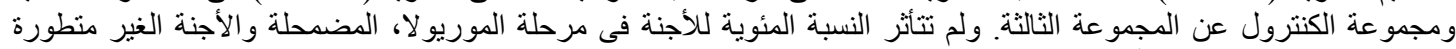
بالمعاملة بمستخلص الثنترول عن الثناى الأخضر.

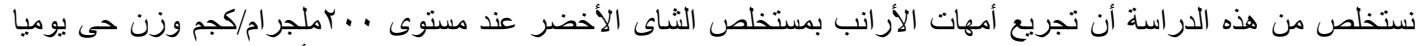

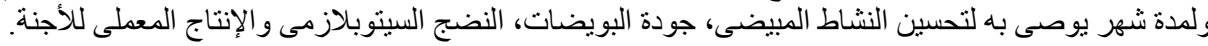


Table (1): Effect of GT extract treatment on ovarian activity of doe rabbits.

\begin{tabular}{lcccc}
\hline \multirow{2}{*}{ Item } & G1 (Control) $)$ & $\begin{array}{c}\text { GT extract level } \\
(200 \mathrm{mg} / \mathrm{kg})\end{array}$ & $\mathrm{G} 3(400 \mathrm{mg} / \mathrm{kg})$ & \multirow{2}{*}{ \pm SEM } \\
\cline { 3 - 4 } & & $0.018^{\mathrm{b}}$ & $0.019^{\mathrm{a}}$ & 0.001 \\
Relative ovarian weight $(\mathrm{mg})$ & $0.017^{\mathrm{c}}$ & 63.00 & 61.25 & 1.422 \\
Number of visible follicles/doe & 59.00 & $53.50^{\mathrm{a}}$ & $51.00^{\mathrm{ab}}$ & 1.244 \\
Number of oocytes/doe & $47.25^{\mathrm{b}}$ & $84.92^{\mathrm{a}}$ & $83.28^{\mathrm{a}}$ & 0.688 \\
\hline
\end{tabular}

${ }^{a, b}$ and c: Means within the same row having different superscripts are significantly different at $P \leq 0.05$.

Table (2): Effect of GT extract treatment on oocyte category of doe rabbits.

\begin{tabular}{lcccc}
\hline \multirow{2}{*}{ Oocyte category $(\%)$} & \multirow{2}{*}{$\mathrm{G} 1$ (Control) } & \multicolumn{2}{c}{$\mathrm{GT}$ extract level } & \multirow{2}{*}{ \pm SEM } \\
\cline { 3 - 4 } Compact & $55.54^{\mathrm{b}}$ & $70.72^{\mathrm{a}}(\mathrm{Gg})$ & $\mathrm{G} 3(400 \mathrm{mg} / \mathrm{kg})$ & \\
Expanded & 7.88 & 7.07 & $67.67^{\mathrm{a}}$ & 1.634 \\
Denuded & $27.58^{\mathrm{a}}$ & $15.49^{\mathrm{b}}$ & 7.33 & 0.979 \\
Partial denuded & 9.00 & 6.72 & $17.17^{\mathrm{b}}$ & 1.189 \\
\hline a,b and c: Means within the same row having different superscripts are significantly different at $P \leq 0.05$. &
\end{tabular}

Table (3): Effect of GT extract treatment on cumulus expansion rate (\%) of doe rabbits oocytes.

\begin{tabular}{|c|c|c|c|c|c|c|c|}
\hline \multirow{3}{*}{ GTPs level } & \multirow{3}{*}{$\begin{array}{c}\text { Total } \\
\text { oocyte }\end{array}$} & \multicolumn{6}{|c|}{ Cumulus expansion } \\
\hline & & \multicolumn{2}{|c|}{ Full } & \multicolumn{2}{|c|}{ Partial } & \multicolumn{2}{|c|}{ Non } \\
\hline & & $\mathrm{n}$ & $\%$ & $\mathrm{n}$ & $\%$ & $\mathrm{n}$ & $\%$ \\
\hline G1 (Control) & 105 & 72 & $68.57^{\mathrm{c}}$ & 13 & $12.38^{b}$ & 20 & $19.05^{\mathrm{a}}$ \\
\hline G2 (200 mg/kg) & 151 & 122 & $80.79^{\mathrm{a}}$ & 17 & $11.26^{\mathrm{b}}$ & 12 & $7.95^{\mathrm{b}}$ \\
\hline G3 (400 mg/kg) & 138 & 104 & $75.36^{\mathrm{b}}$ & 25 & $18.12^{\mathrm{a}}$ & 9 & $6.52^{\mathrm{b}}$ \\
\hline \pm SEM & - & \multicolumn{2}{|c|}{1.006} & \multicolumn{2}{|c|}{0.970} & \multicolumn{2}{|c|}{1.318} \\
\hline
\end{tabular}

a,b and c: Means within the same row having different superscripts are significantly different at $P \leq 0.05$.

Table (4): Effect of GT extract treatment on fertilization and developmental competence of doe rabbits oocytes.

\begin{tabular}{lcccccc}
\hline \multirow{2}{*}{ Group } & $\begin{array}{c}\text { Inseminated } \\
\text { oocytes }(\mathrm{n})\end{array}$ & $\begin{array}{c}\text { Fertilized } \\
\text { ova, } \mathrm{n}(\%)\end{array}$ & $2-16$ cell & Morula & Blastocyst & Degenerated \\
\cline { 5 - 7 } $\mathrm{G} 1(\mathrm{Control})$ & 72 & $38\left(52.78^{\mathrm{c}}\right)$ & $11(28.94)$ & $7(18.42)$ & $5\left(13.16^{\mathrm{b}}\right)$ & $15(39.47)$ \\
$\mathrm{G} 2(200$ & 122 & $82\left(67.21^{\mathrm{a}}\right)$ & $20(24.39)$ & $19(23.10)$ & $16\left(19.51^{\mathrm{a}}\right)$ & $27(32.93)$ \\
$\mathrm{mg} / \mathrm{kg})$ & & & & & \\
$\mathrm{G} 3(400$ & 104 & $63\left(60.58^{\mathrm{b}}\right)$ & $17(26.98)$ & $14(13.40)$ & $11\left(10.58^{\mathrm{ab}}\right)$ & $21(33.33)$ \\
$\mathrm{mg} / \mathrm{kg})$ & & 1.321 & 1.722 & 2.270 & 1.435 & 3.079 \\
\pm SEM & - & &
\end{tabular}

